\title{
Edson Campos Bento
}

\section{Avaliação das Condições de Estanqueidade das Fundações e da Ombreira da Hidroelétrica de Laúca - Angola}

Dissertação de Mestrado

Dissertação apresentada como requisito parcial para obtenção do grau de Mestre pelo Programa de PósGraduação em Engenharia Civil do Departamento de Engenharia Civil da PUC-Rio.

Orientador: Prof. Celso Romanel Co-orientador: Prof. Pedricto Rocha Filho 


\section{Edson Campos Bento}

\section{Avaliação das Condições de Estanqueidade das Fundações e da Ombreira da Hidroelétrica de Laúca - Angola}

Dissertação apresentada como requisito parcial para obtenção do grau de Mestre pelo Programa de Pós-Graduação em Engenharia Civil do Departamento de Engenharia Civil do Centro Técnico Científico da PUC-Rio. Aprovada pela Comissão Examinadora abaixo assinada.

Prof. Celso Romanel Orientador Departamento de Engenharia Civil - PUC-Rio

Prof. Pedricto Rocha Filho Co-orientador Departamento de Engenharia Civil - PUC-Rio

Prof. Alberto de Sampaio Ferraz Jardim Sayão Departamento de Engenharia Civil - PUC-Rio

Prof. Ana Cristina Castro Fontenla Sieira Universidade do Estado do Rio de Janeiro

Prof. José Eugenio Leal Coordenador Setorial Centro Técnico Científico PUC-Rio 
Todos os direitos reservados. É proibida a reprodução total ou parcial do trabalho sem autorização da universidade, do autor e do orientador.

\section{Edson Campos Bento}

Graduou-se em Engenharia Civil pela Universidade Jean Piaget de Angola, de Luanda - Angola, em 2010, tendo exercido a profissão de Engenheiro Civil durante o período 2010-2012. Ingressou, em 2012, no curso de Mestrado em Engenharia Civil da Pontifícia Universidade Católica do Rio de Janeiro, na área de Geotecnia, desenvolvendo dissertação de mestrado na linha de pesquisa de fundações de barragens.

Ficha Catalográfica

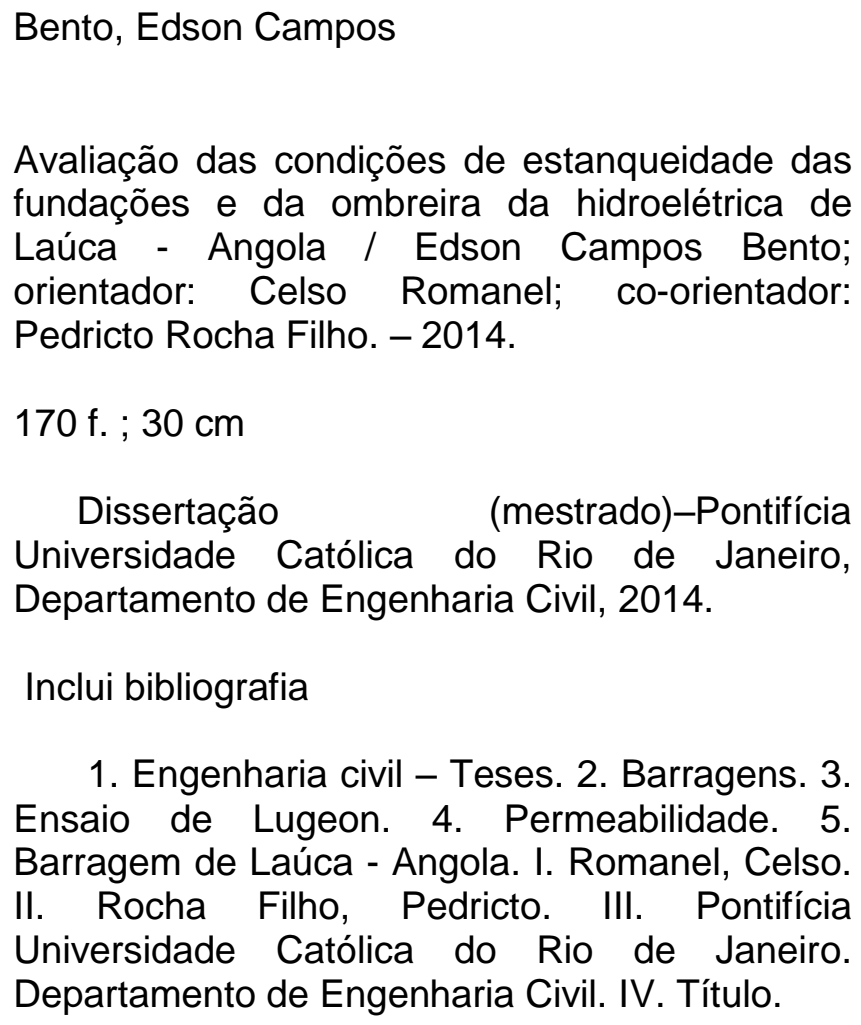

Avaliação das condições de estanqueidade das fundações e da ombreira da hidroelétrica de Laúca - Angola / Edson Campos Bento; orientador: Celso Romanel; co-orientador: Pedricto Rocha Filho. - 2014.

170 f. ; $30 \mathrm{~cm}$

Dissertação (mestrado)-Pontifícia Universidade Católica do Rio de Janeiro, Departamento de Engenharia Civil, 2014.

Inclui bibliografia

1. Engenharia civil - Teses. 2. Barragens. 3. Ensaio de Lugeon. 4. Permeabilidade. 5. Barragem de Laúca - Angola. I. Romanel, Celso. II. Rocha Filho, Pedricto. III. Pontifícia Universidade Católica do Rio de Janeiro. Departamento de Engenharia Civil. IV. Título. 
Dedico esse trabalho, primeiramente, a Deus, pai todo poderoso, sem ele, tal obra não seria possível; aos meus pais, tios, irmãos, primos, sobrinhos, amigos, especialmente, à Maria Emília Amorim Miranda da Conceição.

Aos meus orientadores, professores ao longo desta carreira estudantil, e a todos aqueles que, direta ou indiretamente, me apoiaram.

Sem o incondicional apoio de todos vocês, nada disso se tornaria possível. 


\section{Agradecimento}

Agradeço, primeiramente a Deus, Pai todo poderoso, sem ele, não seria possível a minha existência.

Aos meus avós, pais e tios por terem me mostrado o caminho da escola como uma das melhores formas de ganhar a vida honestamente e pela educação que eles me deram. Espero que desta forma, eles possam se sentir orgulhosos por terem apostado, investido e confiado em mim.

Aos meus queridos irmãos e primos por tudo, pelas vezes que não pude levá-los a passear, porque tinha que estudar, em especial a minha noiva Zuela Capilo. Contudo, eles compreendiam-me. Espero que sigam o mesmo caminho que o meu e que o façam da melhor forma.

Aos meus amigos e colegas Camila Bergmann, Eridson Cardoso, Guillermo Jordan, Gustavo Sobreira, Hugo David, Rui Francisco e Thaís Abreu, pela grande ajuda em todas as etapas deste trabalho.

Ao meu orientador, corpo docente desta Universidade, e, em especial, aos meus colegas que me deram força e ensinamentos para não desistir e, incansavelmente, ofereceram-me conhecimento científico e orientação para a elaboração deste trabalho.

Às empresas que colaboraram para a elaboração deste trabalho: a toda equipe da Odebrecht Angola e, especialmente, à pessoa de António Carlos Daiha que, incondicionalmente, esteve sempre à disposição para a devida colaboração; a Intertechne, em especial aos engenheiros Davi Maranesi e Sérgio Kraemer Montinegro que sempre estiveram prontos para apoiar esta dissertação; a Furnas, à pessoa do engenheiro Edgar Neto e ao Ministério da Construção de Angola, à pessoa do director nacional de infraestrutura José Paulo Kai que sempre foi um pai , amigo, irmão e conselheiro. 
Aos meus orientadores prof. Pedricto Rocha Filho: "Edson o mais importante não é como você entra aqui, mais sim como você sai". E, Celso Romanel. Aos professores Alberto Sayão: "Edson lê este livro como se fosse um romance, não se preocupe com as fórmulas". Michéle Casagrande, Sérgio Fontoura e Euripídes Vargas, pelos seus ensinamentos durante a etapa da minha formação, da realização desta pesquisa e pela oportunidade que me concederam, o meu muito obrigado pelo carinho e paciência.

Agradeço também aos professores da UFRJ/COPPE, Edson Watanabe, Romildo Toledo Filho, Taborda Gárcia, MichèleSchubert Pfeil, Anna Laura Nunes e Ana Cristina (UERJ).

A Pontíficia Universidade Católica do Rio de Janeiro /PUC-Rio, o meu muito obrigado pela oportunidade de ter aberto as portas várias vezes, incondicionalmente, para frequentar o Mestrado. Agradeço também ao programa do governo brasileiro CAPES - Coordenação de Aperfeiçoamento de Pessoal de Nível Superior - pela aposta, oportunidade e pelo apoio financeiro para a realização desta pesquisa, que me concedeu.

À todos que, direta ou indiretamente, me apoiaram ao longo da minha vida, da minha carreira estudantil e da elaboração deste trabalho para a obtenção do grau de Mestre em Engenharia Civil, o meu muito obrigado. 


\section{Resumo}

Bento, Edson Campos; Romanel, Celso; Rocha Filho, Pedricto. Avaliação das Condições de Estanqueidade das Fundações e da ombreira da Hidroelétrica de Laúca - Angola. Rio de Janeiro, 2014. 170p. Dissertação de Mestrado - Departamento de Engenharia Civil, Pontifícia Universidade Católica do Rio de Janeiro.

O aproveitamento hidroelétrico de Laúca, está localizado no km 307,5, do rio Kwanza (medido a partir de sua foz), cerca de $47 \mathrm{~km}$ a jusante do AHE Capanda, próximo à localidade de N'hangueYa Pepe, na província do Kwanza Norte - Angola. A obra teve início no final de 2012 e terminará em 2017. Normalmente, as fundações de barragens são obras projetadas na superfície do globo e apoiadas sobre as rochas, e em muitas dessas rochas encontram-se fraturadas que geram algumas descontinuidades, ocasionando valores elevados da permeabilidade nas fundações de barragens. Esta dissertação tem como principal objetivo avaliar as condições de estanqueidade das fundações do aproveitamento hidrelétrico de Laúca. Esta avaliação foi feita a partir dos resultados de ensaios de perda d'água sob pressão e interpretada através da teoria dos ensaios de Maurice Lugeon, que são realizados em maciços rochosos através de furos de sondagens em diferentes estágios. Estes ensaios têm como finalidade indicar os valores da permeabilidade e do comportamento desses maciços, em relação à percolação d'água através das descontinuidades. Através da teoria de Lugeon, pode-se definir o tipo de escoamento, comportamento do preenchimento nas fraturas e fissuras que indiquem valor representativo da permeabilidade do maciço, que, por sua vez, orientará uma tomada de decisão sobre a necessidade de se adotar alguma intervenção, bem como a adoção de um programa de tratamento das fundações da barragem.

\section{Palavras-chave:}

Barragens; Barragem de Laúca; Ensaio de Lugeon; Permeabilidade. 


\section{Abstract}

Bento, Edson Campos; Romanel, Celso (Advisor); Rocha Filho, Pedricto (Co-Advisor). Evaluation of the flow conditions Through the Foundation of the Laúca Dam - Angola. Rio de Janeiro, 2014. 170p. MSc Dissertation - Departamento de Engenharia Civil, Pontifícia Universidade Católica do Rio de Janeiro.

The Laúca Dam is located at km 307.5 of the Kwanza River (measured from its mouth), about $47 \mathrm{~km}$ downstream from Capanda Hydroelectric Project, near the village of Ya N'hangue Pepe in the province of Kwanza Norte - Angola. Usually dam foundations are designed and constructed along the eroded channel rivers and supported on the rocks, and many of these rocks are fractured, and generate some discontinuities with a high degree of hydraulic conductivity of the dam foundations .This dissertation aims to assess and to evaluate the seepage conditions throughout the foundations of hydroelectric Laúca. This evaluation is normally made using the tests of loss of water with pressure and interpreted using the proposal of Maurice Lugeon, i.e., the well-known in the practice of dam engineering as the Lugeon test. This test is performed in rock masses through boreholes and different stages, aims to determine the hydraulic conductivity and the behavior of the fractured rock mass, taking into the consideration the water flow through the discontinuities and fractures. Using the Lugeon set of results, it can be estimated important engineering characteristics such as: the volume and the type of flow and representatives values of the equivalent mass of the hydraulic conductivity. All this information is useful to establish the grouting procedure and also to verify the performance of the treatment carried out to reduce leakage through the dam foundation.

\section{Keywords}

Dam; Laúca Dam; Lugeon Test; Permeability. 


\section{Sumário}

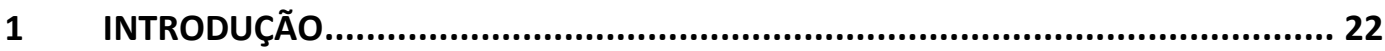

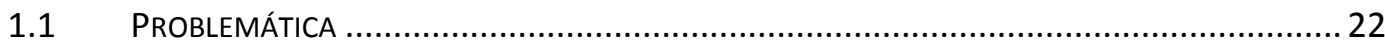

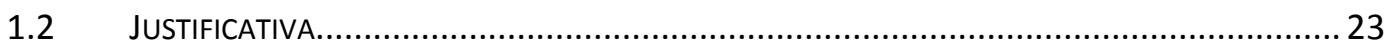

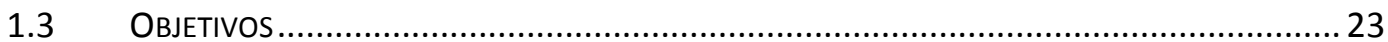

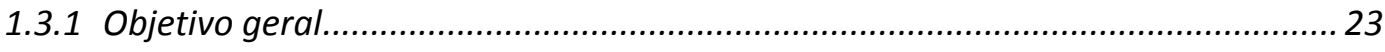

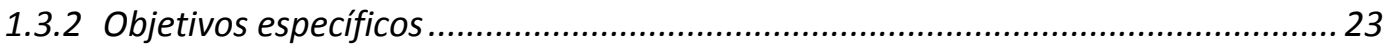

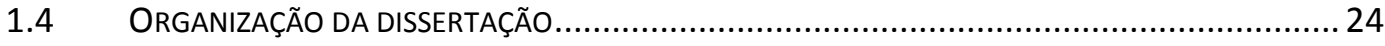

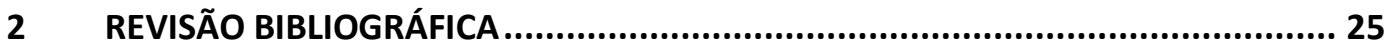

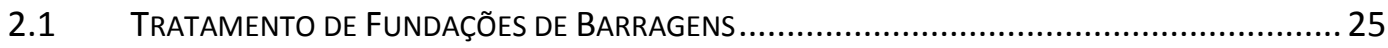

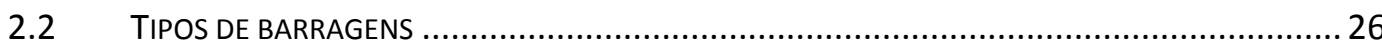

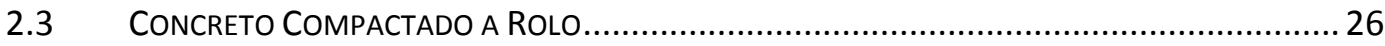

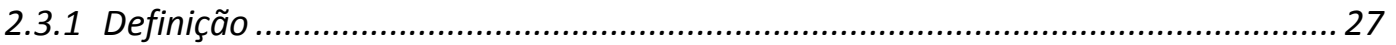

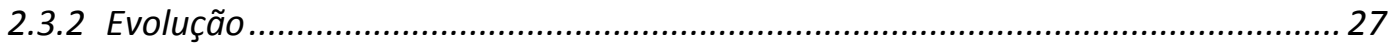

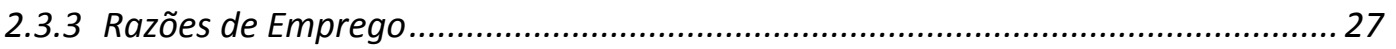

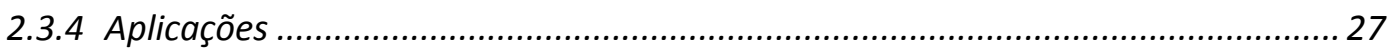

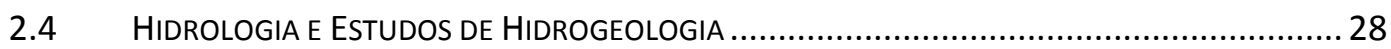

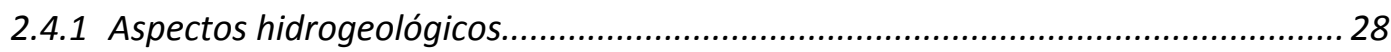

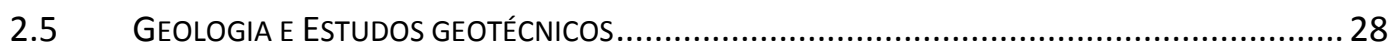

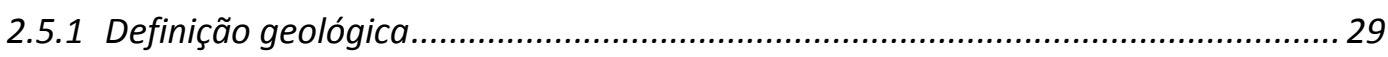

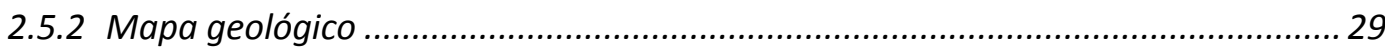

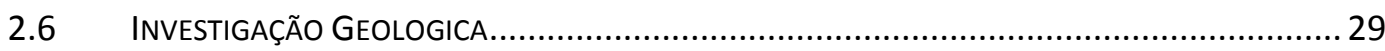

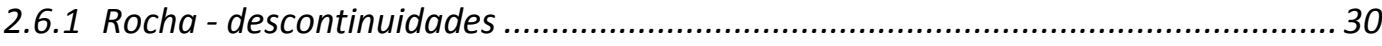

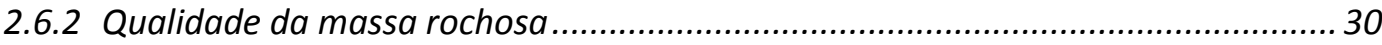

2.7 PROBLEMAS GEOTÉCNICOS DAS FUNDAÇÕES DE UMA BARRAGEM........................................ 31

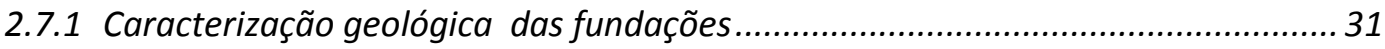

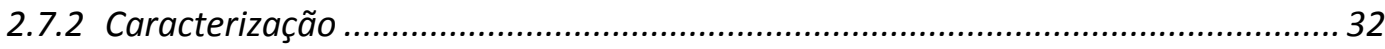

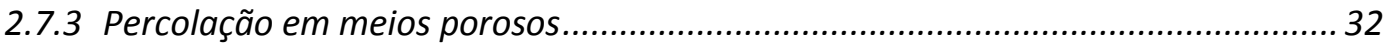

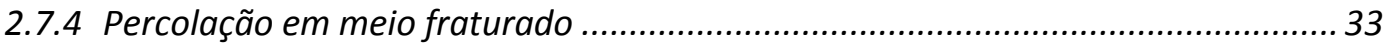

2.8 CLASSIFICAÇÃO GEOMECÂNICA DAS FUNDAÇÕES DE UMA BARRAGEM ................................ 33 


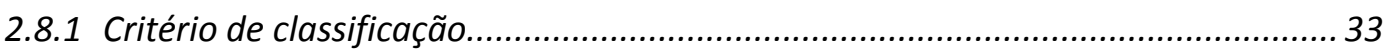

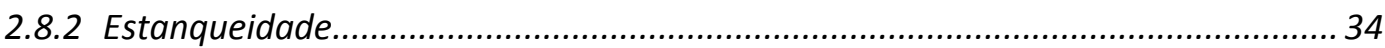

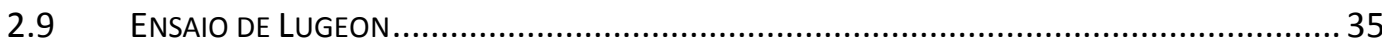

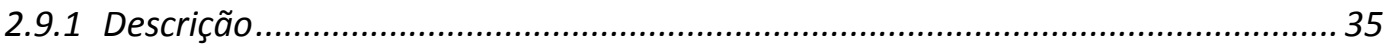

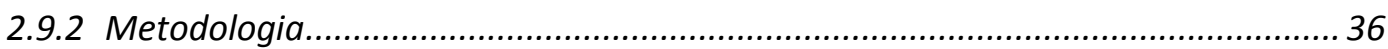

2.9.2.1 Explicação do cálculo ............................................................................................................

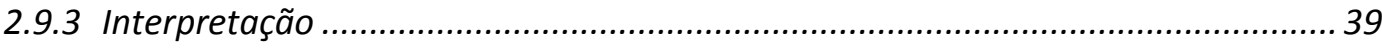

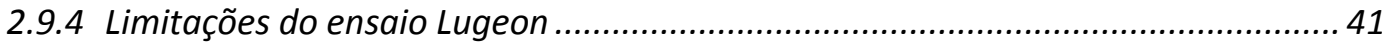

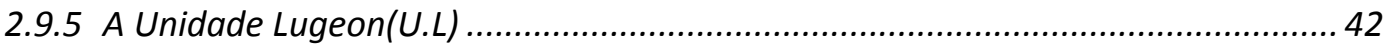

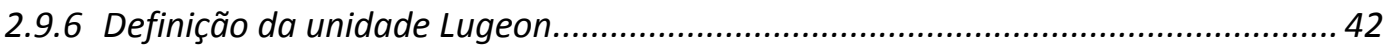

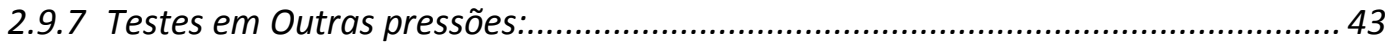

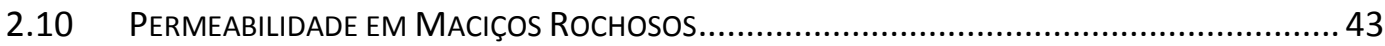

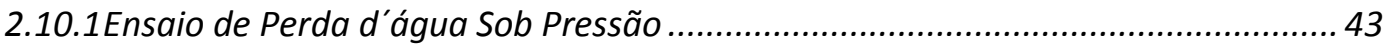

2.10.2Comportamento do Maciço Rochoso e Coeficiente de Permeabilidade (K)............. 44

2.10.3Condicionantes geológicos - geotécnicos e limites de 'permeabilidade' ................50

2.10.4Análise dos ensaios de perda d'água sob pressão .................................................53

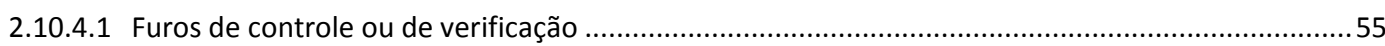

2.10.4.2 Metodologias de controle e formas de análise da eficiência das cortinas de injeção ......................56

2.10.5 Determinação da permeabilidade dos maciços rochosos ..................................57

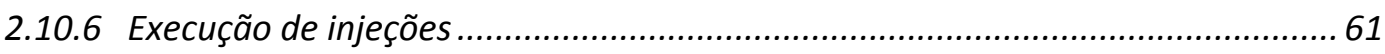

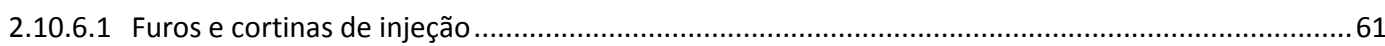

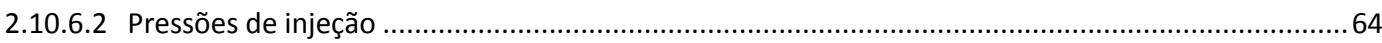

2.10.6.3 Ensaios prévios "insitu” de injeção..............................................................................................67

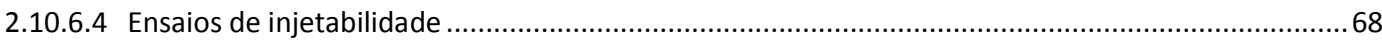

3 ESTUDO DE CASO - HIDRELÉTRICA DE LAÚCA - ANGOLA ....................................70

3.1 CARACTERIZAÇÃO E LOCALIZAÇÃO DO APROVEITAMENTO HIDRELÉTRICO DE LAÚCA ................ 70

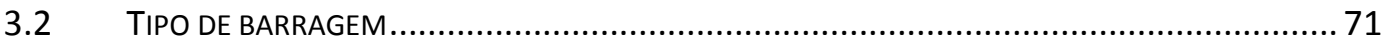

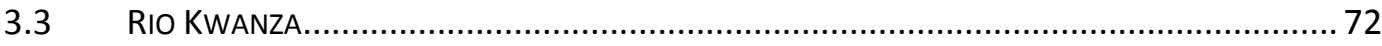

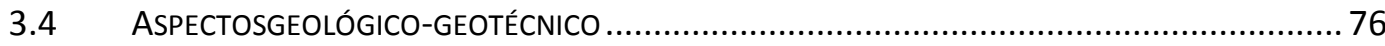

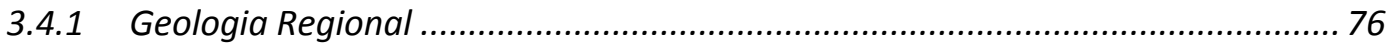

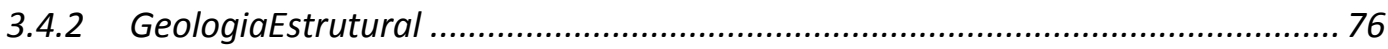

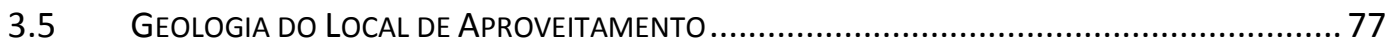

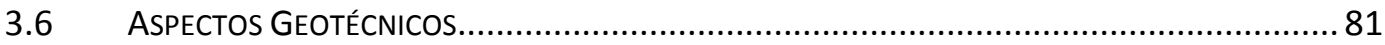

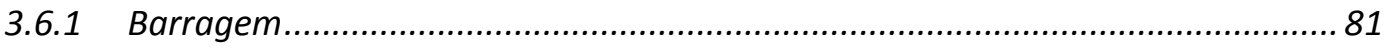

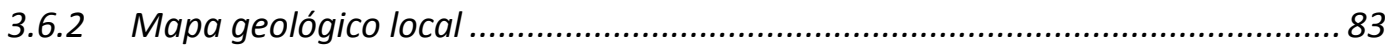

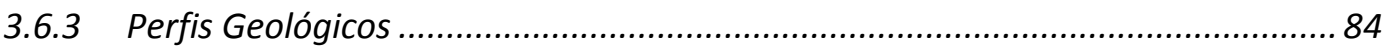


3.6.4 Resumo dos resultados dos ensaios em amostras de rochas.............................. 89

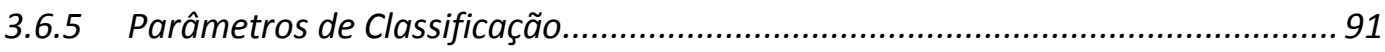

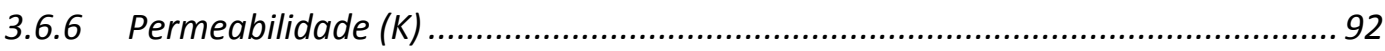

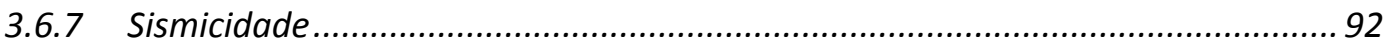

4 APRESENTAÇÃO DOS GRÁFICOS E INTERPRETAÇÃO DOS RESULTADOS

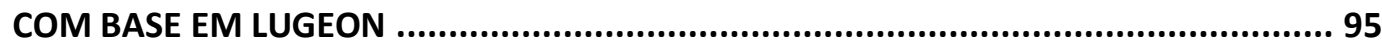

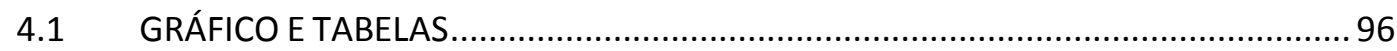

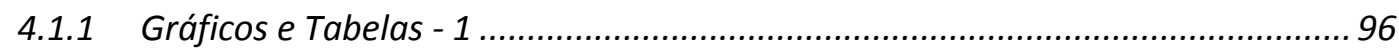

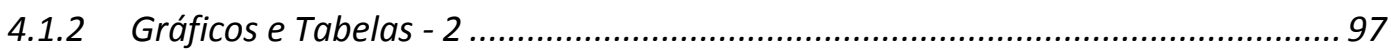

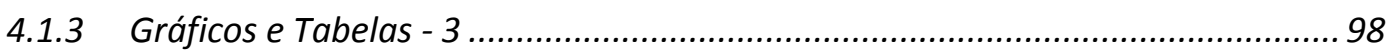

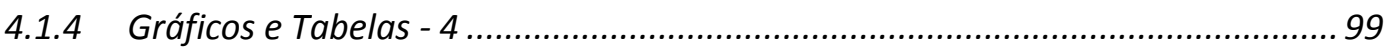

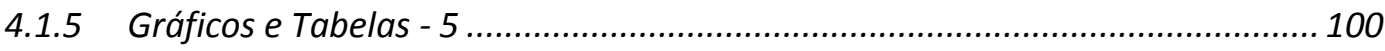

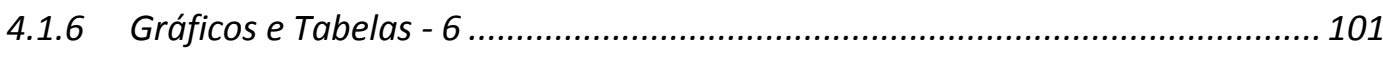

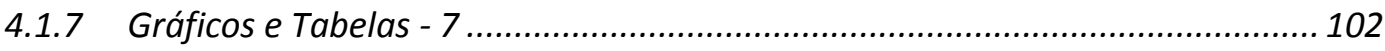

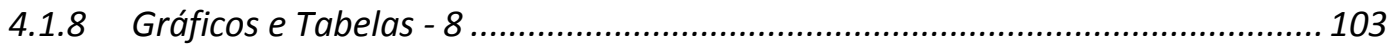

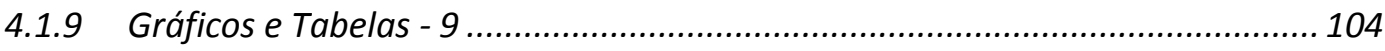

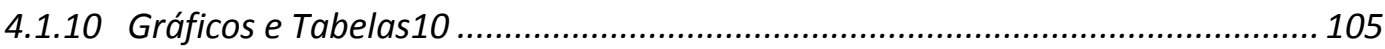

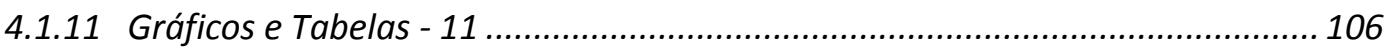

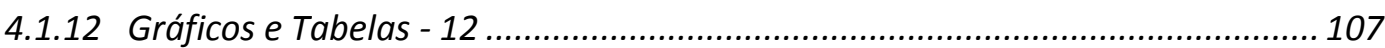

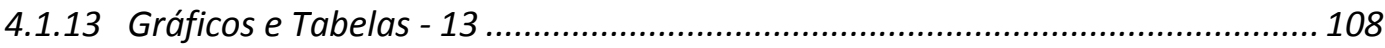

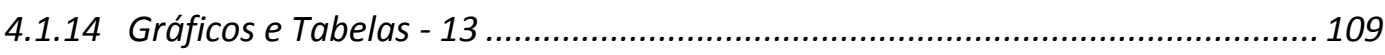

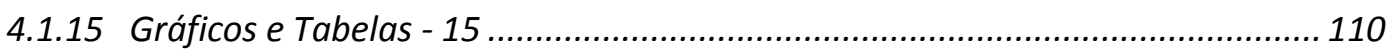

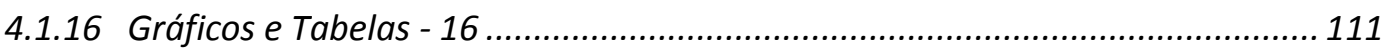

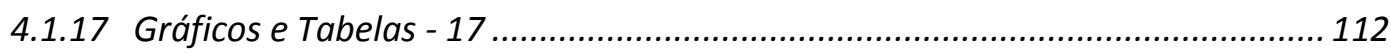

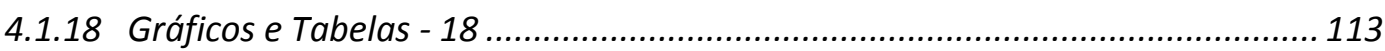

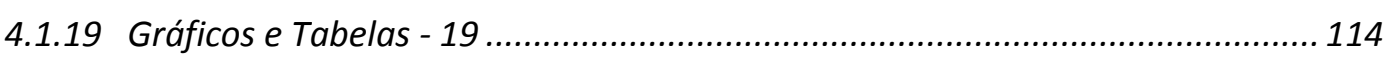

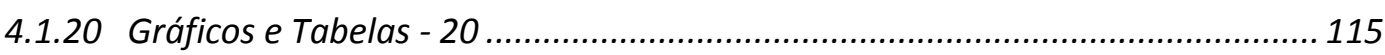

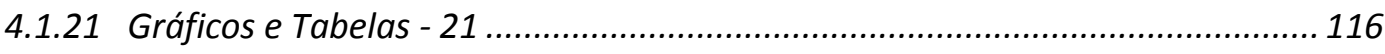

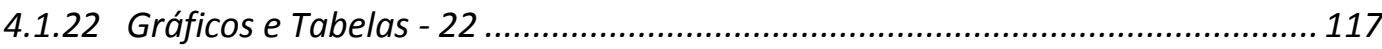

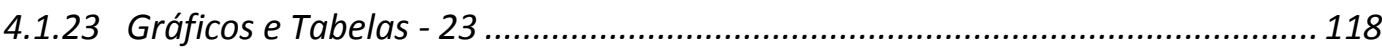

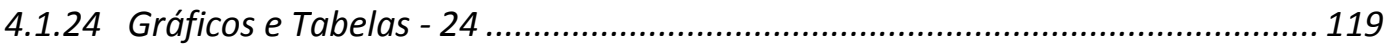

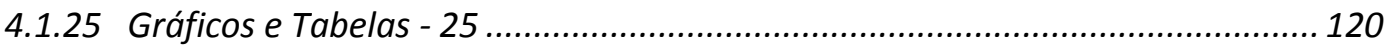

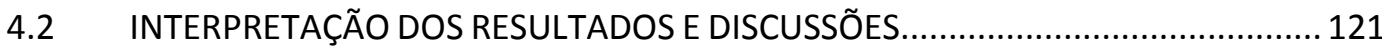

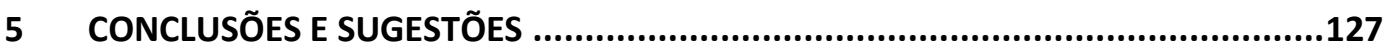

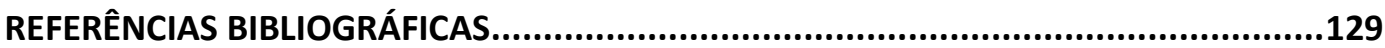


ANEXO 1

133

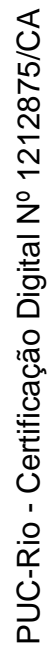




\section{Lista de Figuras}

Figura 2-1 - Esquematização do ensaio tipo Lugeon com obturador duplo

Figura 2-2 - Ensaio de perda d'água 44

Figura 2-3 - Parâmetros de análise de um meio fraturado 45

Figura 2-4 - Modelos de fluxos considerados na análise de ensaios de furo único (Hsieh; Neuman; Simpson, 1983)

Figura 2-5 - Casos teóricos esperados de comportamento do trecho ensaiado (Oliveira et al., 1975)

Figura 2-6 - Comparação das formulas de permeabilidades (Zeigler, 1976).

Figura 2-7- Relação entre a perda d'água e a abertura da fissura das fraturas

Figura 2-8- Variação da permeabilidade de maciços rochosos fraturados, com a profundidade, (Azevedo; Alburquerque Filho, 1998)

Figura 2-9- Valores de vazão específica máxima em cada etapa de injeção na barragem de Xavantes (Rio Paranapema, SP/PR). (Modificado de IPT, 1977 f).

Figura 2-10 - Esquema de montagem para ensaio de perda de carga e perda d'água sob pressão (ABGE, 1975).

Figura 2-11 - Parâmetro do ensaio de perda d'água sob pressão (ABGE, 1975).

Figura 2.12 - esquema das etapas de injeção pelo método ascendente (Modificado de Boudeaux, 1980).

Figura 2.13 - Esquema das etapas de injeção pelo método ascendente (Modificado de Boudeaux, 1980).

Figura 2.14 - Curva de pressões de injeção $x$ profundidade segundo a prática norte-americana (Modificado de Sabarly, 1968). 
Figura 2.15- Esquema de montagem americano para injeção de calda de cimento (IPT, 1984).

Figura 2.16 - Esquema de montagem europeu para injeções de calda de cimento (IPT, 1984).

Figura 2-17- Representação gráfica da (1) "regra européia" e (2) "regra americana"

Figura 2.18- "Curva" e valores máximos de pressões de injeções em função da profundidade, propostas e adotadas em projetos de barragens brasileiras (Modificado de Sampaio, 1983).

66

Figura 3.1 - Barragem de Laúca.

Figura 3.2 - Barragem de cambambe.

Figura 3.3 - Vista da encosta da margem direita (fluxo para a esquerda).

Figura 3.4 - Fratura de alívio aberta.

79

Figura 3.5 - Principais lineamentos mapeados na área.

80

Figura 3.6 - Vista da área do emboque, com a falha 1 marcada.

80

Figura 3.7 - Vista da encosta da margem direita, na área afetada pela falha 2 (fluxo para a esquerda).

Figura 3.8 - Calcario Poroso.

Figura 3.9 - Aspecto da encosta da margem direita, com os negativos formados na encosta.

Figura 3.10 - Aspecto da encosta na área da central principal.

83

Figura 3.14 - Mapa geológico local - planta.

84

Figura 3.15 - Perfil geológico da margem direita.

Figura 3.16 - Perfil geológico do eixo da barragem.

Figura 3.17 - Perfil geológico da margem esquerda.

Figura 3.20 - Mapa da sismicidade de Angola de acordo com a base de dados sismológica usada no estudo de ameaça sísmica. 


\section{Lista de Gráficos}

Gráfico 4.1 - Vazão Equivalente x Pressão Efetiva - ensaio número 1

Gráfico 4.2 - Pressão Efetiva $x$ Lugeon -ensaio número 1

Gráfico 4.3 - Vazão Equivalente x Pressão Efetiva - ensaio número 2.

Gráfico 4.4 - Pressão Efetiva x Lugeon - ensaio número 2.

Gráfico 4.5 - Vazão Equivalente x Pressão Efetiva- ensaio número 3 Gráfico 4.6 - Pressão Efetiva x Lugeon - ensaio número 3

Gráfico 4.7 - Vazão Equivalente x Pressão Efetiva ensaio número 4 Gráfico 4.8 - Pressão Efetiva x Lugeon - ensaio número 4

Gráfico 4.9- Vazão Equivalente $\times$ Pressão Efetiva ensaio número 1

Gráfico 4.10- Pressão Efetiva x Lugeon - ensaio número 1

Gráfico 4.11 - Vazão Equivalente x Pressão Efetiva - ensaio número 2

Gráfico 4.12 - Pressão Efetiva x Lugeon - ensaio número 2

Gráfico 4.13 - Vazão Equivalente x Pressão Efetiva - ensaio número 3 Gráfico 4.14 - Pressão Efetiva $x$ Lugeon - ensaio número 3

Gráfico 4.15 - Vazão Equivalente x Pressão Efetiva - ensaio número 4

Gráfico 4.16 - Pressão Efetiva x Lugeon - ensaio número 4

Gráfico 4.17- Pressão Efetiva x Lugeon - ensaio número 1 Gráfico

4.18- Vazão Equivalente $x$ Pressão Efetiva - ensaio número 1

Gráfico 4.19- Pressão Efetiva $\times$ Lugeon - ensaio número 2 Gráfico 4.20 -Vazão Equivalente x Pressão Efetiva - ensaio número 2

Gráfico 4.21- Pressão Efetiva x Lugeon - ensaio número 3.Gráfico 4.22- Vazão Equivalente x Pressão Efetiva - ensaio número 3.

Gráfico 4.23 - Pressão Efetiva x Lugeon - ensaio número 4.Gráfico 
Gráfico 4.25 - Vazão Equivalente x Pressão Efetiva - ensaio número 1.

Gráfico 4.26 - Pressão Efetiva x Lugeon - ensaio número 1.

Gráfico 4.27 - Vazão Equivalente x Pressão Efetiva - ensaio número 2

Gráfico 4.28- Pressão Efetiva x Lugeon - ensaio número 2

Gráfico 4.29 - Vazão Equivalente x Pressão Efetiva - ensaio número

Gráfico 4.30- Pressão Efetiva x Lugeon - ensaio número 3.

Gráfico 4.31 - Vazão Equivalente x Pressão Efetiva - ensaio número 4

Gráfico 4.32- Pressão Efetiva x Lugeon - ensaio número 4.

Gráfico 4.33 - Vazão Equivalente x Pressão Efetiva - ensaio número 5.

Gráfico 4.34- Pressão Efetiva x Lugeon - ensaio número 5.

Gráfico 4.35 - Vazão Equivalente x Pressão Efetiva - ensaio número

6.

Gráfico 4.36 - Pressão Efetiva x Lugeon - ensaio número 6

Gráfico 37 - Vazão Equivalente x Pressão Efetiva - ensaio número 7.

Gráfico 38- Pressão Efetiva x Lugeon - ensaio número 7.

Gráfico 4.39 - Vazão Equivalente x Pressão Efetiva - ensaio número-8.

Gráfico 4.40 - Pressão Efetiva x Lugeon - ensaio número 8.

Gráfico 4.41 - Vazão Equivalente x Pressão Efetiva - ensaio número-1.

Gráfico 4.42- Pressão Efetiva x Lugeon - ensaio número 1.

Gráfico 4.43 - Vazão Equivalente x Pressão Efetiva - ensaio número 1.Gráfico 4.44- Pressão Efetiva x Lugeon - ensaio número 1.

Gráfico 4.45 - Vazão Equivalente x Pressão Efetiva - ensaio número-2.

Gráfico 4.46- Pressão Efetiva x Lugeon - ensaio número 2. 
Gráfico 4.47 - Vazão Equivalente x Pressão Efetiva - ensaio número

3.

Gráfico 4.48- Pressão Efetiva x Lugeon - ensaio número 3.

Gráfico 4.49 - Vazão Equivalente x Pressão Efetiva - ensaio

número

4.

Gráfico 4.50- Pressão Efetiva x Lugeon - ensaio número 4.

Gráfico 4.51 - Vazão Equivalente x Pressão Efetiva - ensaio número

5.

Gráfico 4.52 - Pressão Efetiva x Lugeon - ensaio número 5.

Gráfico 4.53 - Vazão Equivalente x Pressão Efetiva - ensaio

número

6.

Gráfico 4.54 - Pressão Efetiva x Lugeon - ensaio número 6.

Gráfico 4.55 - Vazão Equivalente x Pressão Efetiva - ensaio número

Gráfico 4.56 - Pressão Efetiva x Lugeon - ensaio número 7. Gráfico 4.57 - Vazão Equivalente x Pressão Efetiva - ensaio número 8. Gráfico 4.58- Pressão Efetiva x Lugeon - ensaio número 8.

Gráfico 4.59 - Vazão Equivalente x Pressão Efetiva - ensaio número

9.

Gráfico 4.60- Pressão Efetiva x Lugeon - ensaio número 9.

Gráfico 4.61- Vazão Equivalente x Pressão Efetiva - ensaio número 10.

Gráfico 4.62 - Pressão Efetiva x Lugeon - ensaio número 10.

Gráfico 4.63 - Vazão Equivalente x Pressão Efetiva - ensaio número

11.

Gráfico 4.64- Pressão Efetiva x Lugeon - ensaio número 11. 


\section{Lista de Tabelas}

Tabela 1 - Magnitudes de pressão normalmente usada para cada fase de ensaio.

Tabela 2 - Condições das descontinuidades do maciço rochoso associadas a gamas de valores de absorção em Lu (adaptado de Houlsby, 1976).

Tabela 3- Síntese da interpretação dos ensaios Lugeon (modificado de Quiñones-Rozo, 2010)

Tabela 4- Equações mais frequentes no cálculo da permeabilidade

Tabela 5 - Dados básicos do projeto da hidrelétrica de Laúca Angola.

Tabela 6 - Dimensionamento das estruturas hidrelétrica de Laúca - Angola.

Tabela 7 - Resultados dos ensaios em amostras de rochas.

Tabela 8 - Sondagens executadas.

Tabela 9 - Logs - Parâmetros de Classificação

Tabela 10 - Permeabilidade

Tabela 11 - Pontuação para definir Categorias de Risco de Barragens de acordo com o Boletim 72 do ICOLD (1989), USCOLD 1996. (Pontos entre parêntesis)

Tabela 12 - Categorização do risco ICOLD, Boletín 72 (1989), USCOLD 1999.

Tabela 4-13- Tipo de escoamento, fraturamento e colmatação ensaio número 1, SR 101.

Tabela 4.14 - Tipo de escoamento, fraturamento e colmatação ensaio número 2, SR 101.

Tabela 4.15 - Tipo de escoamento, fraturamento e colmatação ensaio número 3, SR 101. 
Tabela 4.16 - Tipo de escoamento, fraturamento e colmatação ensaio número 3, SR 101.

Tabela 4.17 - Tipo de escoamento, fraturamento e colmatação ensaio número 1, SR 108.

Tabela 4.18 - Tipo de escoamento, fraturamento e colmatação ensaio número 2, SR 108.

Tabela 4.19 - Tipo de escoamento, fraturamento e colmatação ensaio número 3, SR 108.

Tabela 4.20 - Tipo de escoamento, fraturamento e colmatação ensaio número 4, SR 108.

Tabela 21 - Ensaio de Perda d'água - ensaio número 1, SR 101.

Tabela 22 - Ensaio de Perda d'água - ensaio número 2, SR 10.

Tabela 23 - Ensaio de Perda d'água - ensaio número 3, SR 101.

Tabela 24 - Ensaio de Perda d'água - ensaio número 4, SR 101.

Tabela 25 - Ensaio de Perda d'água - ensaio número 7, SR 101.

Tabela 26 - Ensaio de Perda d'água - ensaio número 8, SR 101.

Tabela 27 - Ensaio de Perda d'água - ensaio número 1, SR 108.

Tabela 28 - Ensaio de Perda d'água - ensaio número 2, SR 108.

Tabela 29 - Ensaio de Perda d'água - ensaio número 3, SR 108.

Tabela 30 - Ensaio de Perda d'água - ensaio número 4, SR 108.

Tabela 31- Ensaio de Perda d'água - ensaio número 5, SR 108.

Tabela 32 - Ensaio de Perda d'água - ensaio número 6, SR 108.

Tabela 33 - Ensaio de Perda d'água - ensaio número 7, SR 108.

Tabela 34 - Ensaio de Perda d'água - ensaio número 8, SR 108.

Tabela 35 - Ensaio de Perda d'água - ensaio número 1, SR 109.

Tabela 36 - Ensaio de Perda d'água - ensaio número 2, SR 109.

Tabela 37 - Ensaio de Perda d'água - ensaio número 1, SR 110.

Tabela 38 - Ensaio de Perda d'água - ensaio número 2, SR 110.

Tabela 39 - Ensaio de Perda d'água - ensaio número 3, SR 110.

Tabela 40 - Ensaio de Perda d'água - ensaio número 4, SR 110.

Tabela 41 - Ensaio de Perda d'água - ensaio número 5, SR 110.

Tabela 42 - Ensaio de Perda d'água - ensaio número 6, SR 110.

Tabela 43 - Ensaio de Perda d'água - ensaio número 7, SR 110.

Tabela 44 - Ensaio de Perda d'água - ensaio número 8, SR 110. 
Tabela 45 - Ensaio de Perda d'água - ensaio número 1, SR 104.

Tabela 46 - Ensaio de Perda d'água - ensaio número 2, SR 104.

Tabela 47 - Ensaio de Perda d'água - ensaio número 3, SR 104.

Tabela 48 - Ensaio de Perda d'água - ensaio número 4, SR 104.

Tabela 49 - Ensaio de Perda d'água - ensaio número 5, SR 104.

Tabela 50 - Ensaio de Perda d'água - ensaio número 6, SR 104.

Tabela 51 - Ensaio de Perda d'água - ensaio número 7, SR 104.

Tabela 52 - Ensaio de Perda d'água - ensaio número 8, SR 104.

Tabela 53 - Ensaio de Perda d'água - ensaio número 9, SR 104.

Tabela 54 - Ensaio de Perda d'água - ensaio número 10, SR 104.168

Tabela 55 - Ensaio de Perda d'água - ensaio número 11, SR 104.169

Tabela 56 - Ensaio de Perda d'água - ensaio número 12, SR 104.170

Tabela 57 - Tabela Ensaio de Perda d'água - ensaio número 13,

SR 104. 


\section{Símbolos}

$\mathrm{V}(\mathrm{m} / \mathrm{s})$ - velocidade média do escoamento

Pmax $\left(\mathrm{kgf} / \mathrm{cm}^{2}\right)$ - pressão máxima

D (m) - profundidade

Q (1/min) - vazão

$\mathrm{L}-$ litro

$\mathrm{P}_{0}\left(\mathrm{kgf} / \mathrm{cm}^{2}\right)$ - pressão padrão

$\mathrm{P}\left(\mathrm{kgf} / \mathrm{cm}^{2}\right)$ - pressão de ensaio

$\mathrm{Km}(\mathrm{cm} / \mathrm{s})$ - permeabilidade do maciço rochoso

$\mathrm{Kf}(\mathrm{cm} / \mathrm{s})$ - permeabilidade da descontinuidade.

$\mathrm{Kr}(\mathrm{cm} / \mathrm{s})$ - permeabilidade da matriz rochosa

$a(\mathrm{~mm})$ - abertura das descontinuidades

$\mathrm{b}(\mathrm{mm})$-espaçamento das descontinuidades

$\mathrm{g}\left(\mathrm{m} / \mathrm{s}^{2}\right)$-aceleração da gravidade

$\mathrm{v}\left(\mathrm{m}^{2} / \mathrm{s}\right)$-viscosidade cinemática

Lm(m) - distância radial a partir da seção ensaiada correspondente a 100\%

de perda de carga piezométrica

$\mathrm{r}(\mathrm{mm})$ - raio do furo

Hc - carga piezométrica no centro do trecho ensaiado

P.E $\left(1 / \mathrm{min} / \mathrm{m} / \mathrm{kgf} / \mathrm{cm}^{2}\right)$ - perda d' água especifica

QE $(1 / \mathrm{min} / \mathrm{m})$ - vazão especifica

$\mathrm{CE}\left(\mathrm{kgf} / \mathrm{cm}^{2}\right)$ - pressão efetiva

F- função (diâmetro do furo e do comprimento (L) do trecho ensaiado)

H (m) - carga da coluna d' água

$\operatorname{Pm}\left(\mathrm{kgf} / \mathrm{cm}^{2}\right)$ - pressão manométrica

C (m) - comprimento da tubulação (utilizado no cáculo da perda de carga)

$\mathrm{N}(\mathrm{m})$ - profundidade do N.A

$\mathrm{N}^{\prime}(\mathrm{m})$ - é altura do N.A em casos de artesianismo.

$\mathrm{K}$ - coeficiente de permeabilidade $(\mathrm{cm} / \mathrm{s})$

Ht - carga hidráulica do techo em metro

$\mathrm{Lt}$ - comprimento do trecho em metro 